Max-Planck-Institut für demografische Forschung

Max Planck Institute for Demographic Research

Konrad-Zuse-Strasse 1 - D-18057 Rostock - GERMANY

Tel +49 (0) 3812081 - 0; Fax +49 (0) 3812081 - 202;

http://www.demogr.mpg.de

MPIDR WORKING PAPER WP 2015-003

JULY 2015 (REVISED OCTOBER 2016)

\title{
Time-to-death patterns in markers of age and dependency
}

Tim Riffe (riffe@demogr.mpg.de)

Pil H. Chung

Jeroen Spijker

John MacInnes

This working paper has been approved for release by: Mikko Myrskylä (sekmyrskyla@demogr.mpg.de), Head of the Laboratory of Population Health and Head of the Laboratory of Fertility and Well-Being.

(C) Copyright is held by the authors.

Working papers of the Max Planck Institute for Demographic Research receive only limited review. Views or opinions expressed in working papers are attributable to the authors and do not necessarily reflect those of the Institute. 


\title{
Time-to-death patterns in markers of age and dependency
}

\author{
Tim Riffe*1, Pil H. Chung ${ }^{2}$, Jeroen Spijker ${ }^{3}$, and John MacInnes ${ }^{4}$ \\ ${ }^{1}$ Max Planck Institute for Demographic Research \\ ${ }^{2}$ Department of Demography, University of California, Berkeley \\ ${ }^{3}$ Centre d'Estudis Demogràfics \\ ${ }^{4}$ School of Social and Political Science, University of Edinburgh
}

October 4, 2016

\begin{abstract}
We aim to determine the extent to which variables commonly used to describe health, wellbeing, and disability in old-age vary primarily as a function of years lived (chronological age), years left (thanatological age), or as a function of both. We analyze data from the US Health and Retirement Study to estimate chronological age and time-to-death patterns in 78 such variables. We describe results from the birth cohort born 1915-1919 in the final 12 years of life. Our results show that most markers used to study well-being in old-age vary along both the age and time-to-death dimensions, but some markers are exclusively a function of either time to death or chronological age, and others display different patterns between the sexes.
\end{abstract}

*riffe@demogr.mpg.de

We would like to thank the editors of this issue, who also organized the 2014 conference that inspired us to undertake this project. We also thank two anonymous reviewers whose comments improved the manuscript greatly. Research reported in this manuscript was supported by the U.S. National Institute On Aging of the National Institutes of Health under award numbers R01-AG011552 and R01-AG040245, the Spanish Ministry of Economy and Competitiveness under award RYC-2013-14851, and the UK ESRC grant $\mathrm{ES} / \mathrm{K} 004611 / 1$. The content is solely the responsibility of the authors and does not necessarily represent the official views of the funding agencies. 


\section{Background}

For an individual, age across the life course consists of two components: time since birth and time to death, the chronological and thanatalogical dimensions of age, respectively. In the aggregate, thanatological age is determined by the mortality rate schedule to which a birth cohort is subject until its extinction. Individuals do not know their thanatological age with certainty. To guess this quantity one projects an expectation of lifespan ${ }^{1}$ based on scenarios or extrapolations of how mortality rates might change over time. Data classified by chronological age, like census population counts, can be reclassified into thanatological age in this way (Brouard 1986).

Prospectively, decreasing mortality is equivalent to moving population into higher thanatological ages, thereby increasing remaining life expectancy (Sanderson and Scherbov 2005). In this case, the notion and measure of future remaining lifespan is elastic, subject to uncertainty. In retrospect (after the death of a cohort), the thanatological age structure of a cohort at a given past point in time is a fixed characteristic. Since a closed birth cohort is akin to a stationary population, ${ }^{2}$ one may be tempted to assume that since chronological and thanatological age structures are symmetrical in stationary populations (Brouard 1989, Vaupel 2009, Villavicencio and Riffe 2016) that the patterns of demographic characteristics within cohorts might also demonstrate an analogous kind of symmetry. This is not so; even in the case of stationary populations or extinct cohorts, the age profiles of other demographic characteristics in the population are decidedly different when viewed chronologically versus thanatologically. If the demographic characteristics in question are states, such as health states, one can confirm that for cohorts the mean duration spent in each state is indeed identical, no matter whether measured by chronological or thanatological age. Cohort expectancies are immune from age classification biases. However, distinct patterns emerge in period aggregates due to an interaction between lifespan variation and the age profiles of demographic characteristics.

Some life transitions, states, and changes in state intensities are almost exclusively a function of time to death. When we state that a characteristic is a function of either age perspective we do not imply that age causes the

\footnotetext{
${ }^{1}$ Lifespan is used throughout as a synonym for chronological age at death, or thanatological age at birth. These concepts are identical with length of life, which is not to be confused with life expectancy, the mean length of life..

${ }^{2}$ The age structure of a birth cohort over time is proportional to the survivorship column of its lifetable, which is proportional to the stable age structure determined by the Lotka-Euler renewal model when the intrinsic growth rate is equal to zero.
} 
given characteristic to vary, but rather that a characteristic varies in some smooth, regular, or parsimonious way over age. There are other instances where chronological age captures almost all pertinent variation. In cases where a characteristic strongly varies as a function of time to death, the common practice of aggregation over chronological age may misrepresent time trends and misguide analyses about change over time and expectations for the future. Measurement of the end-of-life trajectories of characteristics is useful in such cases as a way of separating mortality patterns from patterns in characteristics themselves. Characteristic measurements are taken while the respondent is alive, but thanatological age at each observation is unknown until the date of death is known, and it is therefore retrospectively assigned. This final analytical step lends clarity to the understanding of how characteristics vary within and between lifespans.

Incorporating a time-to-death perspective in demographic studies is especially important when assessing the impact of "population aging." To the extent that the health, welfare, and social care demands of a population are functions of thanatological rather than chronological age structure, forecasts of the social and economic "costs" of aging that are based only on chronological age profiles are prone to bias (Stearns and Norton 2004).

Research exploring time-to-death patterns has been done in other domains, and topics examined can be roughly categorized into two types: 1) things that are a function of apparent or perceived time to death (Hamermesh 1985, Hurd and McGarry 1995, Carstensen 2006, Gan et al. 2004, Bíró 2010, Salm 2010, van Solinge and Henkens 2010, Cocco and Gomes 2012, Payne et al. 2013, Balia 2013), and 2) things that are a function of actual time to death (Miller 2001, Seshamani and Gray 2004, Werblow et al. 2007, Wolf et al. 2015, Stearns and Norton 2004). The first kind are mostly studies on cognitive transitions and economic or health behaviors, while the second kind are mostly studies on health expenditure, except Wolf et al. (2015), which proposes a model to separate latent time-to-death trajectories. A third branch of research relates perceived and actual remaining lifetime (Perozek 2008, Delavande and Rohwedder 2011, Post and Hanewald 2012, Kutlu-Koc and Kalwij 2013). In this paper we will expand the second group, focusing on a broad range of questions from ten waves of the US Health and Retirement Study (RAND 2013).

We aim to understand the end-of-life age patterns of various dimensions of morbidity, as measured by a set of 78 characteristics and indices. To do this, we score the degree to which these characteristics vary in terms of thanatological age, chronological age, or both. In all, we define four different age and lifespan pattern families, which we use to classify the end-of-life 
prevalence of each characteristic tested. The pattern of variation exhibited by a given characteristic ought to determine how we measure, understand, and respond to the characteristic. We show that often chronological age ought to be used in conjunction with thanatological age in order to classify patterns, but in many cases chronological age provides no information at all, and it even obfuscates true temporal patterns.

Our analytical approach is retrospective rather than prospective, meaning that no lifetable assumptions are made in the measurement of thanatological age, and no censoring adjustments are necessary. Although more data are available for earlier and later cohorts, we report results only for the cohort born from 1915 to 1919, which contains the most extensive set of observations in the dataset used. In the following section we describe the methods in greater detail. We then demonstrate the four primary age patterns by way of example, and summarize all characteristics tested in terms of these four patterns. Finally, we discuss some implications and applications of this work.

\section{Data \& Method}

All findings reported in this paper are based on data from the US Health and Retirement Study (HRS). We use version M of the RAND edition of the data, which is conveniently merged across all ten waves available as of 2013. These data are free to download, and all details of data processing and methods are made freely available in an open code repository. ${ }^{3}$

We restrict the sample to only those individuals born between 1900 and 1930 who died between 1992 and 2011, which narrows the dataset down to 37,051 interviews of 9,238 individuals. Of these interviews, 8,137 are from the 1,919 individuals who died from the 1915-1919 cohort. Observations from earlier and later cohorts are kept for the sake of adding information when fitting models to the data.

Underpinning this investigation are a series of demographic surfaces indicating the average prevalence of a given marker along chronological and thanatological time axes within a series of quinquennial birth cohorts, from which we focus only on the central 1915-1919 birth cohort. This visual tool is similar to but orthogonal to the familiar Lexis surface. Figure 1 orients the reader with the temporal coordinates we use. This diagram represents the various possible lifespans within a given birth cohort, with an arbitrary

\footnotetext{
${ }^{3}$ This repository includes $\mathrm{R}$ code used to process data, as well as generate results and figures: https://github.com/timriffe/ThanoEmpirical
} 
Figure 1: Chronological age and thanatological age over the lifecourse of a birth cohort

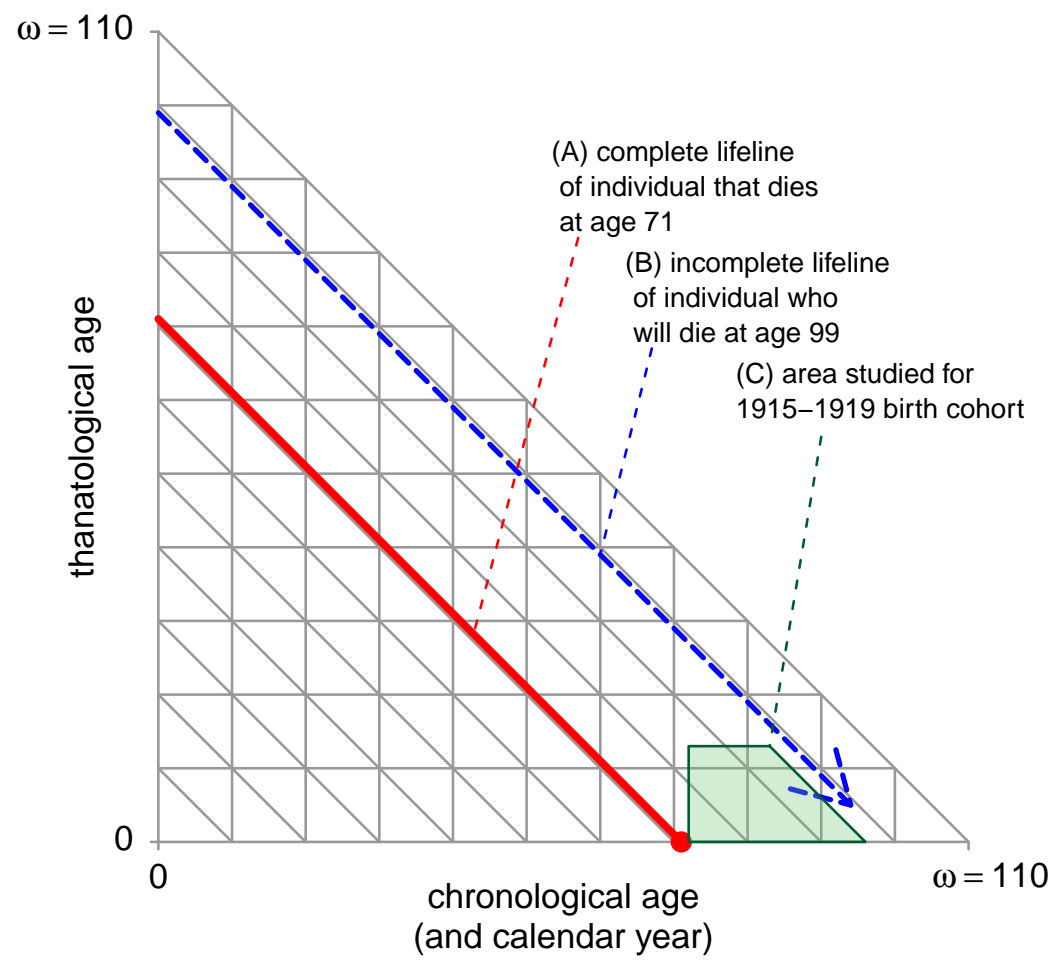

final age, $\omega$, of 110 . One's thanatological age at birth is equal to one's chronological age at death, such that both axes close out with $\omega$. Members of the birth cohort are born on the left side of the diagram, at chronological age zero and with an unknown $y$ coordinate (remaining lifetime) at the time of birth. Lifelines advance downward and to the right, where the downward direction indicates the approach to death, and the rightward direction represents both the progression of calendar years and chronological age. The blue arrow (B) indicates a hypothetical lifeline that will eventually expire at age 99, although this property is unknown until death. The present study contains only complete lifelines, such as that depicted in the color red (A) in Figure 1, which completes its lifespan at age 71 . In this diagram, diagonal 
lines represent death cohorts (or lifespan cohorts), as opposed to the birth cohort diagonals found in the standard Lexis diagram.

We limit the current study to the 1915-1919 cohort due to the characteristics of the data source. Using the HRS, enough observations are available from the 1915-1919 cohort that we can measure the patterns of within the area outlined in green $(\mathrm{C})$ in Figure 1. The left bound of this area is chronological age 72, and the diagonal right bound belongs to the completed lifespan of 95. Since the HRS spans 20 calendar years (1992-2011), the theoretical upper bound of observation of thanatological age is 20. However, individuals in this sample between thanatological ages 13 and 20 (i.e., individuals that entered the study around 1992 and also died around 2011) are scarce, and so we study only thanatological ages less than or equal to 12, ergo the final 12 years of life. As further waves are added to the HRS and mortality linkage continues, the portion of the lifecourse that may be studied in this way will expand.

The 1915-1919 birth cohort was exposed to the 1918 Spanish influenza epidemic as toddlers (1915-1917 cohorts), as infants (1917-1918) cohort, and in-utero (1919 cohort). There is evidence that this exposure manifested in various ways in late life (e.g., Almond 2006, Myrskylä et al. 2013), and so the reader may rightly question whether the results presented here are anomalous. The potential anomalous effects from this cohort are "smoothed-out" in our analysis, due both to the width of the cohort and to the nature of the statistical method we use to estimate aggregate patterns from individual observations. Specifically, loess smoothing borrows information from observations in earlier and later cohorts. Further, at these ages we assume that other risk factors, some of them cumulative over the life course, and senescence itself likely drive health patterns to a much greater extent than might early-life selection or late-life onsets of poor health due to the Spanish influenza.

We also verify that patterns for this cohort do not appear visually distinct from those found in earlier and later cohorts. More importantly, our goal here is not to describe the end-of-life experience of this particular birth cohort, but to add resolution to the measurement and description of aging and morbidity indicators, and contribute to the practice of demography in general.

Age Thanatological age is calculated for each individual as the lag between interview and death dates expressed as decimal years. Chronological age is calculated as the lag between birth and interview date in decimal years. 
Each individual is therefore assigned a chronological and thanatological age at each interview, along with measures of our variables of interest. Since we are interested in viewing characteristics over both chronological age and thanatological age simultaneously, we require observations spread over a wide range of combinations of thanatological and chronological age.

Version M of the RAND HRS dataset runs from 1992 to 2011, which means that each birth cohort is observed over a different range of ages. For example, the 1925-1929 cohort enters observation in 1992 at age 62 (at the youngest) and acheives a maximum completed age of 85 by the end of 2011 . On the other end, the 1905-1909 enters the HRS in 1992 at age 82 at the youngest and has a maximum completed lifespan of 105 by the last wave in 2011, albeit with few observations at the upper extreme. Results from these and other birth cohorts are also obtained from these data, but portions of these surfaces are based on fewer data points (lifespans $>100$ ) or ages in which labor market exits appear to drive patterns at least as much as senescence (ages $<67$, approximately). We focus on the 1915-1919 cohort because its observation window is centered on the chronological ages in which most deaths occur and in which most recent mortality improvements in lowmortality countries have occurred, ${ }^{4}$ and because the HRS provides a good density and spread of data points over this window. The lower and upper age bounds vary if questions were not available in the first, second or final waves.

Characteristics We aim for a broad overview of the age variation across different dimensions of old-age disability and wellbeing. For this reason we select a wide variety of questions from the HRS data. These include questions grouped roughly into the following categories:

1. Activities of Daily Living (ADL): six items, and two composite indices.

2. Instrumental Activities of Daily Living (IADL): seven items and two composite indices.

3. Health Behaviors: five items.

4. Functional Limitations: six items.

5. Chronic Conditions: eight items and one composite index.

\footnotetext{
${ }^{4}$ Own calculations based on UN data (United Nations, Department of Economic and Social Affairs, Population Division 2013). The modal ages at death for the 1915-1919 cohort are 80-81 for males and around 87 for females. These calculations are based on partially observed cohort mortality rates, $M(x)$ (Human Mortality Database 2015).
} 
6. Cognitive Function: 15 items and two composite indices.

7. Psychological Wellbeing: nine items and one composite index.

8. Healthcare Use: 14 items.

The specific variables included in our survey are found in the appendix tables following the same numbering scheme as above. In all, we summarize results from 78 individual and composite items. We exclude variables that were not asked continuously from at least wave 3 through 9 . Variables not available in the first or second wave have left age bounds at ages higher than 72 , whereas items not asked in wave ten have upper lifespan bounds that are below 95 .

Each survey question must be in a format suitable for numeric operations. This requires some compromises in data quality, since some coded responses are less directly quantifiable, and our translation of categorical or ordinal responses to numeric values was at times based on selected cutpoints. For example, respondents were asked if they felt depressed. We assigned 0 to answers of "no" and 1 to answers of "yes". As an example of ordinate recoding, self-reported health had possible responses of "excellent", "very good", "good", "fair", and "poor", which we assigned values of $0,0,0,1$, and 1 , respectively. In this way, population means for this kind of variable can be interpreted as prevalences.

Variables with compact or bounded numeric responses were rescaled to range from 0 to 1 . Variables with no clear bounds or very large upper bounds, such as body mass index or number of hospital visits were not rescaled. These rescalings are intended to simplify the visual interpretation of surfaces, as a diagnostic, and they do not alter the quantitative summary measures we use later. Some response sets for particular questionnaire items changed between waves. In these cases, we attempted to assign numerical codes that were consistent over the transition. These recodes are imprecise, but they are good enough to meet the goals of this study. In other words, the surfaces we present are not exact measurements, but are meant to provide impressions about how characteristics change over age. ${ }^{5}$

Weighting The population universe of the HRS and this study is the resident population of the United States. Therefore person weights are needed

\footnotetext{
${ }^{5}$ The pre-processing of variables is full of details that would clutter this paper. Rather than a lengthy and detailed appendix describing the case by case treatment of variables, please consult the annotated code in the open repository.
} 
in order to estimate population-level means. One difficulty with the HRS is that the institutionalized population is treated as a second target population. In all waves but 5 and 6 , there are no person weights assigned to individuals living in institutions. We try to impute missing person-weights according to some simple assumptions. If the individual was assigned a weight in a previous wave, we carry this weight over as a constant, unless there was also a non-zero weight in a future interview, in which case we assign the weight according to a within-individual linear pattern. Individuals and interviews that still have missing person-weights after this procedure are discarded from our study. Person weights compensate for minor detectable attrition in the HRS (Kapteyn et al. 2006), which for our purposes may be considered unbiased ${ }^{6}$.

Loess smoothing Direct tabulations of the weighted data are legible if all birth cohorts are combined, but doing this distorts results due to cohort composition bias. To overcome birth cohort heterogeneity within surfaces, we use birth cohorts as a third time dimension. Tabulations within this three dimensional space are noisy, and so we enhance surface legibility by using a non-parametric local smoother. We specify a loess model of the given characteristic over chronological age, thanatological age, and quinquennial birth cohorts, using all observations of since-deceased individuals from the 1900 through the 1934 birth cohorts. We fit the model using the loess() function in base $\mathrm{R}$ (Cleveland et al. 1992, R Core Team 2013) ${ }^{7}$ to the weighted individual-level data for each sex separately, and then predict a surface for the 1915-1919 birth cohort within the study area outlined in green (C) in Figure 1. Weighting is therefore explicit by person-weights, and implicit by point density within the three temporal dimensions. ${ }^{8}$

\footnotetext{
${ }^{6}$ Small biases in the survey only appear with respect to baseline characteristics that we do not consider. Attrition due to health conditions, e.g., mental impairment, is mostly mitigated due to the use of proxy respondents in such situations (Weir et al. 2011).

${ }^{7}$ Using the fitted model, surfaces are produced using the related loess prediction function, predict.loess(). The smoothing parameter, spar, is set to 0.7 for the results we present in the paper. All results were also produced using smoothing parameters of .5, and .9 , and we concluded that the specific choice of smoothness does not drive results. The three predictor dimensions are not normalized, in order to preserve year units.

${ }^{8}$ Note that smoothing over these three particular time dimensions is not an overidentification. Within a cohort, to smooth over thanatological age, chronological age and completed lifespan would be an overidentification, similar to the familiar APC problem. The full set of lifespan indices the demographer has to choose from are: birth cohort, death cohort, chronological age, thanatological age, complete lifespan, and period. Within this set of six lifespan dimensions, some combinations invoke overidentification and others do not. For instance, it would be possible to smooth over years lived, years left, and period
} 


\section{Results}

We first present examples of four surfaces that exemplify the major ways in which characteristics tend to vary temporally over the lifespan within a birth cohort. These four major patterns of variation provide a way to categorize and understand markers of aging. We summarize the results of our set of 78 characteristics by calculating Pearson correlation coefficients for each of these four axes and display results graphically, as well as in an appendix shaded table.

Four major surface axes In most situations it is obvious to the eye whether a variable operates over thanatological age or over chronological age, but there are many instances where both are at play, or where the relationship is complex. We first present surfaces representing psychological problems for males (Figure 2a) and back pain for females (Figure 2b). These two surfaces are examples of thanatological and chronological characteristics, respectively.

From the direction of the contours on the surface in Figure 2a, we conclude that the chances of ever having been diagnosed with psychological problems increases with the approach to death and not with the advancing of chronological age, at least in the window of observation studied here. However, since the risk of death itself also increases according to an approximate exponential pattern in these same ages, aggregating individual results by chronological age produces an increasing pattern over age for this same characteristic (see Figure 3). In this case, the apparent chronological age pattern is due to an interaction between the thanatological pattern seen in Figure 2a and the age pattern of mortality itself. We argue that it is imprecise to consider chronological age a risk factor for characteristics that display such strong thanatological patterns, as an apparent chronological age pattern along said margin is a deceptive artifact. Instead, such characteristics appear to more closely operate as effects of the body shutting down or possibly as a signal on average that death is not far off, a demographic corroboration of substantive findings in the psychology literature (Carstensen 2006). Ceteris paribum, mortality itself ought to be a good proxy for characteristics that are highly thanatological. Some characteristics studied here display patterns that are strongly thanatological.

Figure $2 \mathrm{~b}$ tells just the opposite story about back pain for females. Back pain is a function of chronological age, at least at the population level until

in this case, but birth cohorts are the more meaningful category for this study. 
around chronological age 85 . This is the dominant way of thinking about most aspects of the aging process. In these ages, back problems provide no information about remaining years of life. Of the characteristics included in this study, only current smoking, arthritis, and self reports of current versus former memory exhibit such clear chronological patterns (both for males and females).

Other informative patterns also exist among the set of characteristics studied. These include characteristics that vary by lifespan, which display downward diagonal contours in surface plots. Characteristics that vary by lifespan appear constant within lifespans. These are often characteristics that determine lifespan. Ever smoking displays such a pattern, as seen in Figure 4a for females of the 1915-1919 cohort. This pattern is also a corroboration of science and common sense: smoking kills, eventually (at least in this range of lifespans). Other variables that display similar patterns in this window of the lifespan include lung disease among males (this is largely redundant with the former), dental visits in the previous two years (females), and diabetes among females. Sometimes such patterns combine in complex ways worthy of further study.

The fourth major pattern of contour variation runs perpendicular to lifelines. One characteristic that clearly displays this pattern is ever having been diagnosed with high blood pressure among males. This characteristic varies by lifespan, and thanatological age within lifespan for this window of study. In other words, longer lifespans display later onset but greater eventual odds of having been diagnosed with high blood pressure. Arithmetically, chronological age - thanatological age is the operative predictor of blood pressure. For example, for such characteristics, the condition of a 70 -year old with five remaining years of life may resemble that of an 80-year old with 15 remaining years of life. Such characteristics are not very useful alone for predicting eventual lifespan. ${ }^{9}$ Some characteristics appear to follow this pattern, albeit with contour lines at angles less than $45^{\circ}$, which may suggest thanatological morbidity prevalence somehow proportional to length of life. We do not measure this possibility explicitly.

\footnotetext{
${ }^{9}$ We do not have expertise to comment further on blood pressure, but instead only provide an interpretation of the surface presented.
} 
Figure 2: Examples of characteristics that vary along the thanatological and chronological age axes.

(a) Psychological problems (ever) by years lived (x axis) and years left (y axis). Males, 1915-1919 birth cohort.

thanatological age

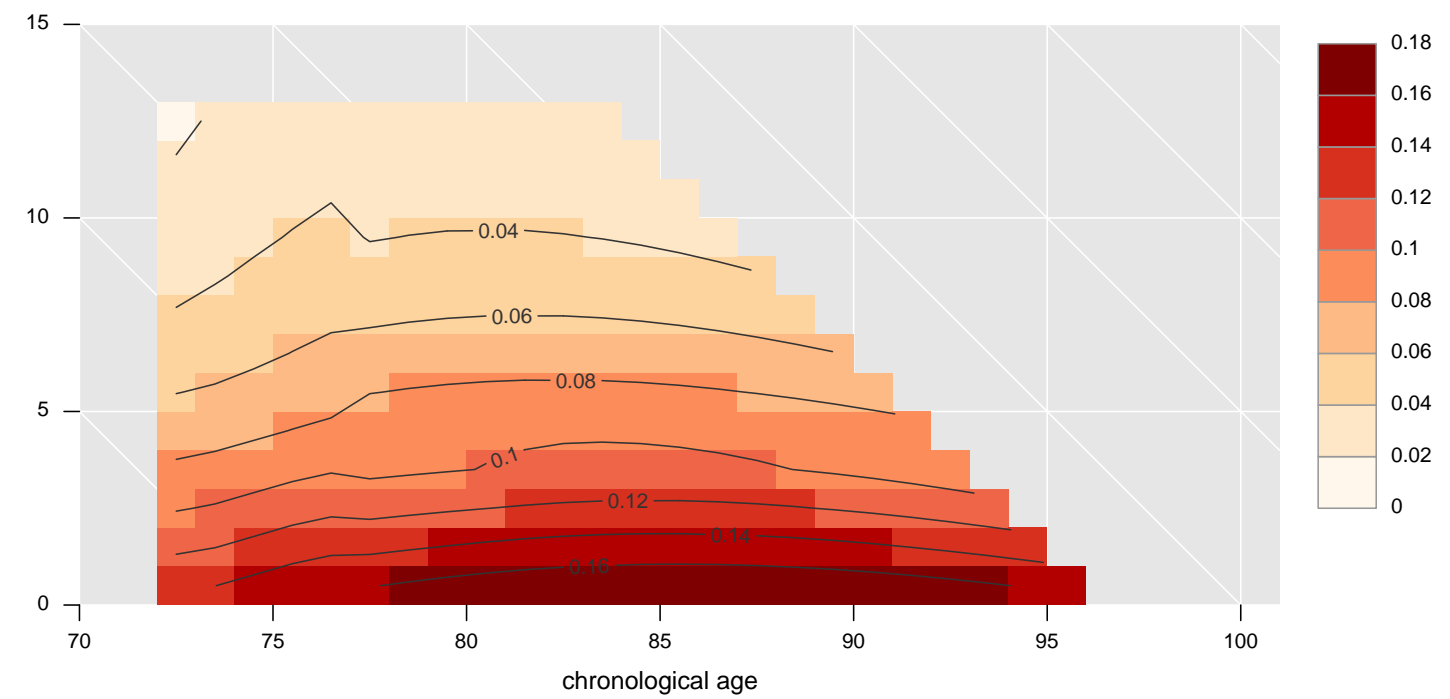

(b) Back Problems by years lived (x axis) and years left (y axis). Females, 1915-1919 birth cohort.

thanatological age
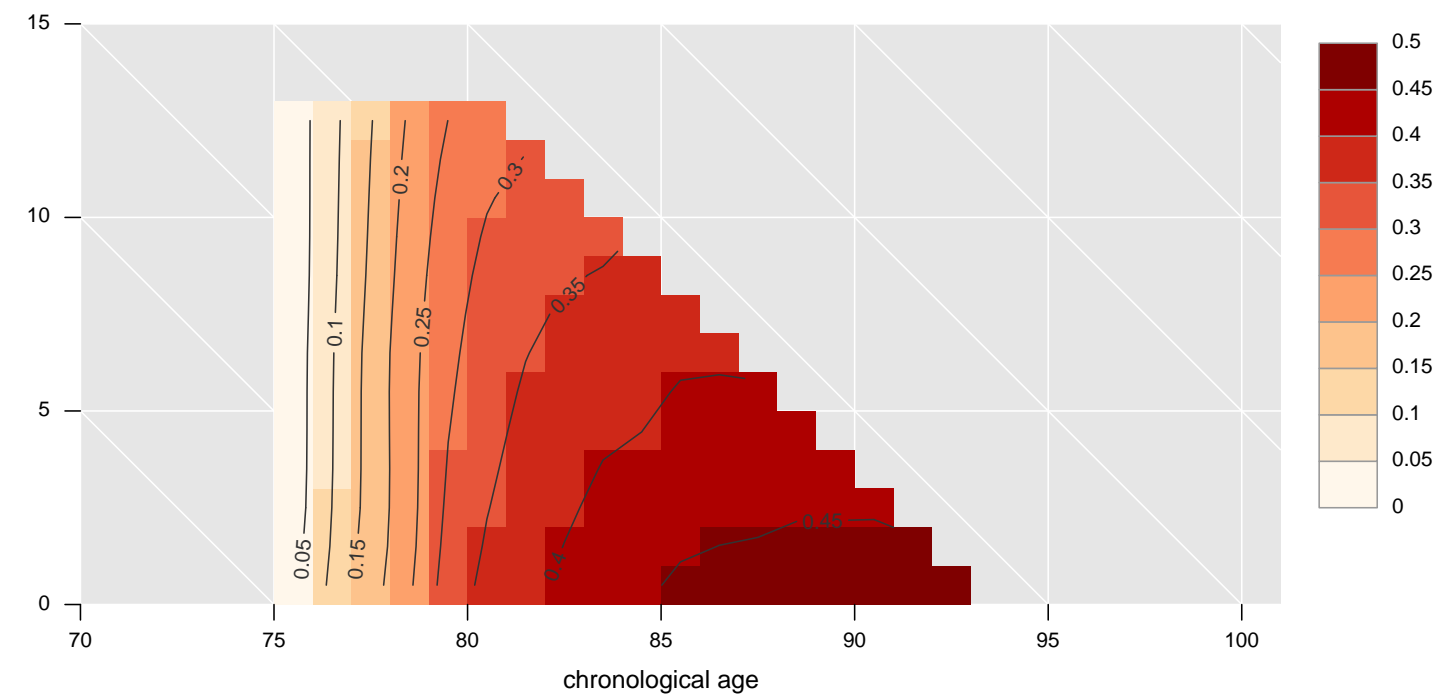
Figure 3: Psychological problems (ever) by chronological age only. Males, 1915-1919 birth cohort. With 95\% confidence bands from loess fit.

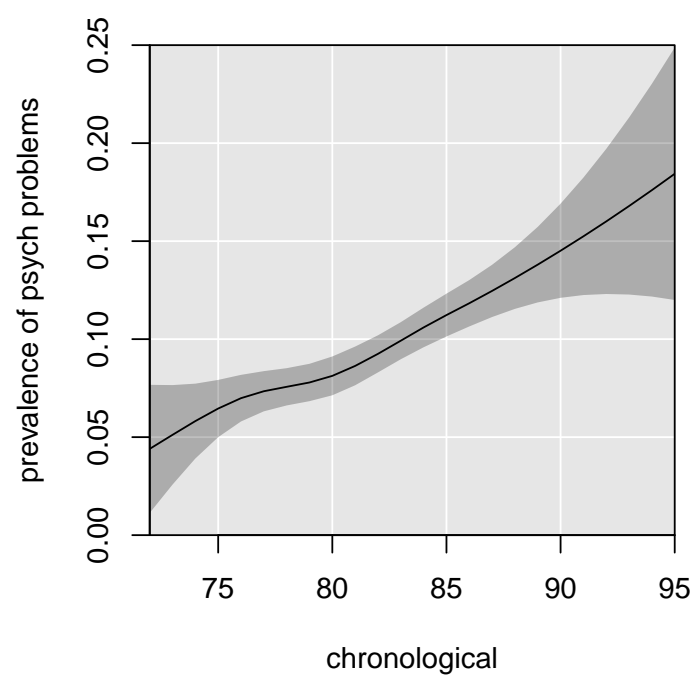


Figure 4: Examples of characteristics that vary by lifespan only or by thanatological age within lifespan.

(a) Smoking (ever) by years lived (x axis) and years left (y axis). Females, 1915-1919 birth cohort.

thanatological age

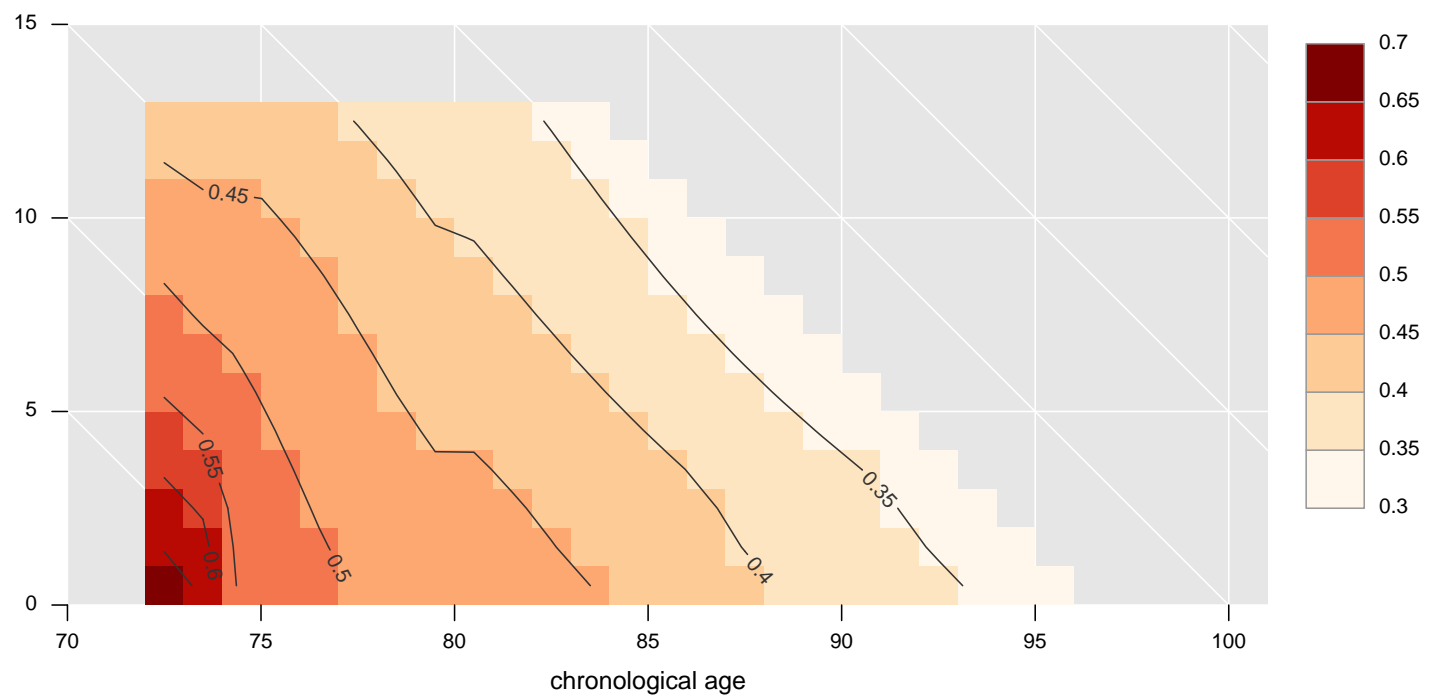

(b) Blood Pressure by years lived (x axis) and years left (y axis). Males, 1915-1919 birth cohort.

thanatological age
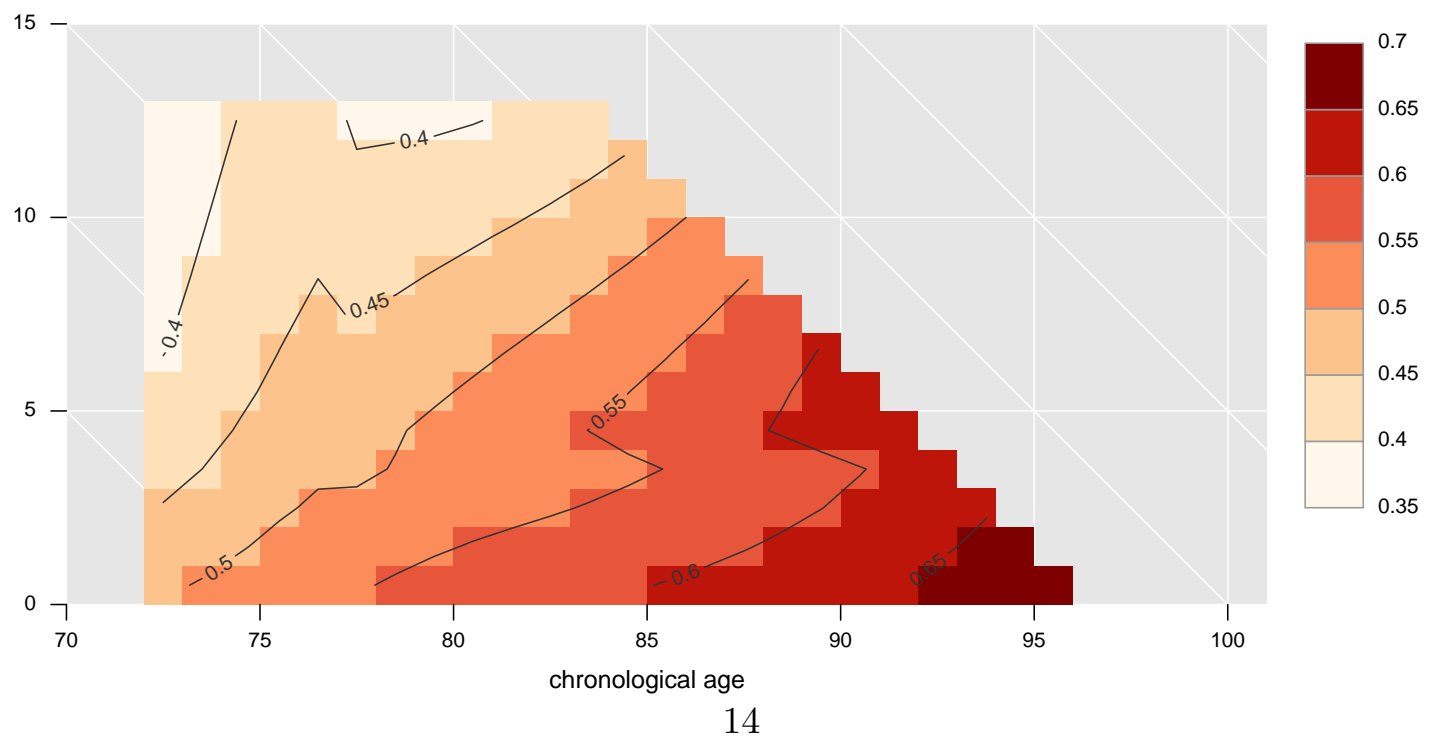
Summary of results for all characteristics We produce surfaces such as those in Figures 2 and 4 for all 78 variables and each sex. We distill each of these surfaces into four Pearson correlation coefficients, each designed to capture the variation along each of the four major patterns explained above. We call the four patterns thanatological age $(\mathrm{T})$, chronological age (A), lifespan $(A+T)(\mathrm{L})$, and mixed $(A-T)(\mathrm{M})$. Most characteristics are well-summarized by either one or two of these patterns. Figure 5 shows the correlation coefficients of all 78 variables binned into count histograms for each sex and major variation pattern separately. This view is meant to give a feel for how common each major pattern of variation might be in commonly measured characteristics. This statistic only captures the rough direction of variation in characteristics, and it does not capture differences in levels or gradient steepness.

The first row of this panel shows that variation by lifespan is weak for most variables, and strong for only a few (ever smoking, and for females having visited a dentist). The second row shows that chronological age is indeed an important aspect of variation for many characteristics, but not all characteristics (e.g., ever having been diagnosed with pyschological problems), and chronological variation is more often strong for females than for males. The third row shows that thanatological age is an important pattern of variation for many variables: the lower tail is thinner than that of chronological age, and there are more cases of strong correlations $(r>0.80)$ in the direction of thanatological variation than of chronological variation. In the distributions over these variables, males tend to more commonly show stronger thanatological age patterns than females, and females tend to show stronger chronological age patterns than males. Finally, the most common pattern in these data are for characteristics to vary strongly as chronological age increases and as thanatological age decreases, M (especially for many ADLs, IADLs, functional limitations, and many variables of cognitive funciton). For females, this is very clearly the dominant pattern among the variables studied. For males, the pattern of variation between characteristics is similar to that of thanatological age. In most cases, for variables with strong patterns of variation in the $\mathrm{M}$ direction, there are also strong correlations in the $\mathrm{A}$ and/or $\mathrm{T}$ directions. Of these, $\mathrm{M}$ is most commonly paired with $\mathrm{T}$. Characteristics that show strong correlation in both $\mathrm{M}$ and $\mathrm{T}$ display surfaces with contour lines slanted less than $45^{\circ}$. A more detailed table of correlation results by variable, pattern, and sex is given in the appendix. 
Figure 5: Distribution of correlation coefficients for each of the four major patterns of variation, all 78 variables examined. L indicates lifespan variation (like Figure 4a), A chronological age (like Figure 2b), T thanatological age (like Figure $2 \mathrm{a}$ ), and $\mathrm{M}$ the mixed type variation (like Figure $4 \mathrm{~b}$ ).

(a) Females

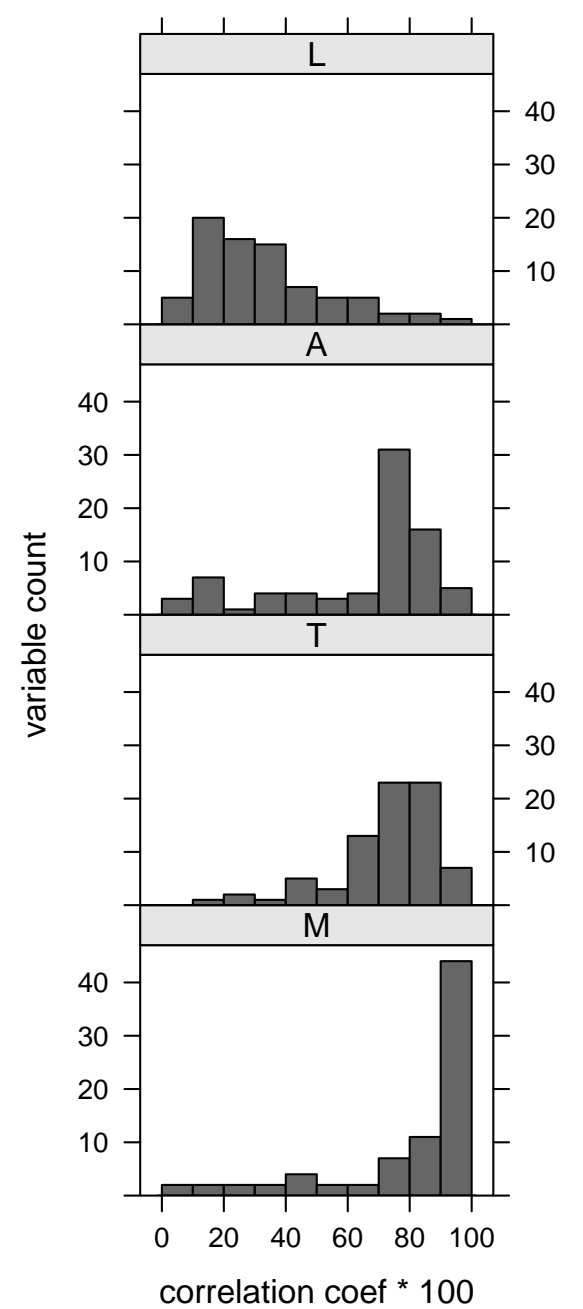

(b) Males

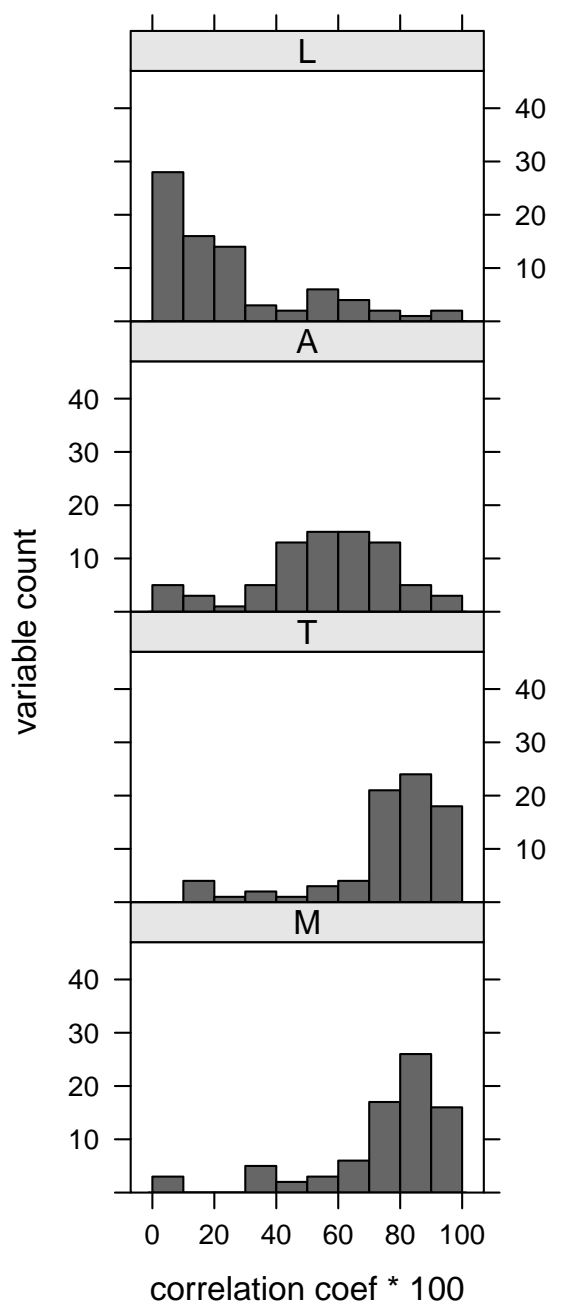




\section{Discussion}

The distribution of tested characteristics with respect to the four primary patterns of variation is striking. Chronological age describes prevalence patterns for many conditions well, but time-to-death patterns are more prevalent among the measures tested. For measures that vary both with the increase of age and the approach to death, the approach to death is more often the stronger of the two measures. Characteristics that vary by length of life are few, but their patterns are clear. The upshot, as illustrated by comparing figures $2 \mathrm{a}$ and 3 , is that representing morbidity or disability variables as chronological age patterns can in many or most cases be misleading as model of morbidity processes, and biased as a basis for prediction.

These empirical findings must be tempered by noting that 1) the summary measure (correlation coefficient) used here blends out some information, 2) these results may not extrapolate to the set of all testable questions in the HRS, and 3) this relationship does not necessarily hold in other windows of the lifespan or other birth cohorts. Comparable results for other five-year birth cohorts in the HRS (1905-1925) are given in the manuscript repository.

Further, the patterns presented here are valid for the whole population (of a given sex) taken together, but were the target population broken down by causes of death (for instance), the patterns may change. For example, imagine hypothetically that the strong thanatological pattern shown in Figure 2 (psychological problems) were driven by strong patterns within individuals that eventually die of suicide, but that other causes of death displayed entirely different patterns with respect to psychological problems. Such cases are easily imaginable for other characteristics and causes of death. At the time of this research, we did not have access to cause of death information from the HRS mortality followup. For detailed investigations of particular characteristics, cause-conditioning surfaces would clearly aid in disentangling morbidity processes, both for purposes of understanding and for cause and time of death prediction.

Research to better document the multidimensional age variation of particular characteristics would benefit from more empirical evidence and further model development. Despite the limitation of this study, we have been able to demonstrate the complex variety of age and lifespan dimensions over which some key aspects of the aging process unfold. All of the indicators we tested are commonly used to describe population aging, and very few of them are exclusively a function of chronological age. If this finding is sustained in other cohorts and populations, and if other indicators here untested also 
display similar temporal complexity, we submit that the common discourse and debate on the nature and impacts of aging ought to be better informed by more judicious measurement and description in terms of thanatological as well as chronological age. This would benefit scientific understanding of health and disability processes, and it would improve the actuarial accuracy of morbidity projections and any policies that count on accurate morbidity projections.

That accounting for time-to-death in predictions of healthcare expenditure reduces bias has already been established in the health economics literature (e.g., Stearns and Norton 2004). A common finding on healthcare expenditure prediction is that in times of mortality improvements, predictions based on chronological age patterns of healthcare expenditure (Sullivanstyle predictions (Sullivan 1971)) tend to overestimate total expenditure (e.g., Geue et al. 2014). Since the patterns of variation among the morbidity dimensions we study are similar to those of healthcare expenditure over chronological age and time-to-death, we here infer that Sullivan-style predictions of morbidity are biased in the same direction. ${ }^{10}$ The consequences of overestimating future morbidity prevalence are complex and varied, ranging from budget misallocations, poor design of social healthcare systems for the elderly, through to to lowered expectations on the benefits of lengthening life.

We hope that the conceptual model of the lifecourse presented here, which complements the Lexis diagram, will be of use to demographers, public health researchers, and epidemiologists. Other combinations of lifespan time dimensions are also possible, and these would highlight different patterns in data (Riffe et al. 2015). The variety and availability of such options, perhaps now placed in starker relief, demands a more nuanced understanding of the temporal accounting that relates demographic time perspectives. Further exploration and experimentation with these formal demographic concepts will lead to a more precise toolkit for demographic measurement and the practice of demography, and ultimately a wiser contribution to the discourse on population aging.

We suggest a selection of extensions to the exploration carried out here. The present variety of analysis must be replicated for more cohorts and populations. A few populations with long-running and fully linked population registers already preside over such information, and we encourage a more thorough exploration of the temporal richness in population change and population characteristics. Large scale panel studies may be motivated to

\footnotetext{
${ }^{10}$ Other work in progress treats this point in greater detail (van Raalte and Riffe 2016).
} 
implement, increase, or improve the quality of mortality follow-up modules. Information on the full age dimensions of health outcomes will be valuable. The good news is that many unlinked panel studies may be linked to death registers in retrospect.

If compared over calendar time, demographic work such as this will provide a more precise answer to the question of morbidity compression. Given the chronological-age ruse exemplified in the case of psychological problems (see Figures 3 versus 2a), it is safe to say that unless retrospective thanatological measurements of morbidity dimensions are undertaken, we do not have direct information about whether compression is (or has been) happening or not. Using the techniques shown here, the researcher may directly estimate the varieties of end-of-life profiles often seen in the literature on morbidity compression (e.g., Fries et al. 2011).

There are also consequences for the popular understanding of aging. By using analyses oriented by the lifecourse diagram, health care providers better situate the association of certain health outcomes with stages of the aging process. This is both a question of allocating resources and a question of how individuals conceive of themselves with respect to age. In this regard, we add to the chorus of researchers working to change the measurement of age to reflect the changing experience of age (see e.g., Sanderson and Scherbov 2013).

The lifecourse surfaces underlying this study highlight important sex differences in the aggregate onset and trajectory of some aspects of morbidity. Some of these differences may corroborate extant findings, such as the malefemale health-survival paradox, and others may provide new understanding to sexual dimorphism in morbidity. Specifically, females have been found to live longer but in worse health than males (e.g., Case and Paxson 2005), and this is consistent with females having somewhat more chronologicallyvarying health patterns than males. In general, these methods and measurements are applicable to describe any between-group disparity in demographic or social outcomes, especially those that directly or indirectly relate to remaining years of life. Numerous other avenues of potential investigation may also be devised from the present work. It is our hope that these results are strongly suggestive and orient future investigation.

\section{References}

Almond, D. (2006). Is the 1918 influenza pandemic over? long-term effects of in utero influenza exposure in the post-1940 us population. Journal of 
political Economy 114(4), 672-712.

Balia, S. (2013). Survival expectations, subjective health and smoking: evidence from share. Empirical Economics 47, 1-28.

Bíró, A. (2010). Subjective mortality hazard shocks and the adjustment of consumption expenditures. Journal of Population Economics 26, 1-30.

Brouard, N. (1986). Structure et dynamique des populations. la pyramide des années à vivre, aspects nationaux et exemples régionaux. Espace, populations, sociétés 4 (2), 157-168.

Brouard, N. (1989). Mouvements et modèles de population. Institut de formation et de recherche démographiques.

Carstensen, L. L. (2006). The influence of a sense of time on human development. Science 312(5782), 1913-1915.

Case, A. and C. Paxson (2005). Sex differences in morbidity and mortality. Demography 42(2), 189-214.

Cleveland, W. S., E. Grosse, and W. M. Shyu (1992). Local regression models. Statistical models in S, 309-376.

Cocco, J. F. and F. J. Gomes (2012). Longevity risk, retirement savings, and financial innovation. Journal of Financial Economics 103(3), 507-529.

Delavande, A. and S. Rohwedder (2011). Differential survival in europe and the united states: Estimates based on subjective probabilities of survival. Demography 48(4), 1377-1400.

Fries, J. F., B. Bruce, and E. Chakravarty (2011). Compression of morbidity 1980-2011: a focused review of paradigms and progress. Journal of aging research 2011. Article ID 261702, 10 pages doi:10.4061/2011/261702.

Gan, L., G. Gong, M. Hurd, and D. McFadden (2004). Subjective mortality risk and bequests. Technical report, National Bureau of Economic Research.

Geue, C., A. Briggs, J. Lewsey, and P. Lorgelly (2014). Population ageing and healthcare expenditure projections: new evidence from a time to death approach. The European Journal of Health Economics 15(8), 885896. 
Hamermesh, D. S. (1985). Expectations, life expectancy, and economic behavior. The Quarterly Journal of Economics 100(2), 389-408.

Human Mortality Database (2015). University of California, Berkeley (USA) and Max Planck Institute for Demographic Research (Germany). Available at www.mortality.org or www.humanmortality.de (data downloaded on February 27, 2015).

Hurd, M. D. and K. McGarry (1995). Evaluation of the subjective probabilities of survival in the health and retirement study. Journal of Human resources 30, S268-S292.

Kapteyn, A., P.-C. Michaud, J. P. Smith, and A. Van Soest (2006). Effects of attrition and non-response in the health and retirement study. Technical report, IZA Discussion paper.

Kutlu-Koc, V. and A. Kalwij (2013). Individuals survival expectations and actual mortality. Netspar Discussion Papers, 2013-013.

Miller, T. (2001). Increasing longevity and medicare expenditures. Demography 38(2), 215-226.

Myrskylä, M., N. K. Mehta, and V. W. Chang (2013). Early life exposure to the 1918 influenza pandemic and old-age mortality by cause of death. American journal of public health 103(7), e83-e90.

Payne, J. W., N. Sagara, S. B. Shu, K. C. Appelt, and E. J. Johnson (2013). Life expectancy as a constructed belief: Evidence of a live-to or die-by framing effect. Journal of Risk and Uncertainty 46(1), 27-50.

Perozek, M. (2008). Using subjective expectations to forecast longevity: Do survey respondents know something we dont know? Demography 45(1), 95-113.

Post, T. and K. Hanewald (2012). Longevity risk, subjective survival expectations, and individual saving behavior. Journal of Economic Behavior 86 Organization 86, 200-220.

R Core Team (2013). R: A Language and Environment for Statistical Computing. Vienna, Austria: R Foundation for Statistical Computing.

RAND (2013, September). RAND HRS Data, Version M. Produced by the RAND Center for the Study of Aging, with funding from the National Institute on Aging and the Social Security Administration. 
Riffe, T., J. Schöley, and F. Villavicencio (2015). A unified framework of demographic time. MPIDR Working Papers WP-2015(8), 22.

Salm, M. (2010). Subjective mortality expectations and consumption and saving behaviours among the elderly. Canadian Journal of Economics/Revue canadienne d'économique 43(3), 1040-1057.

Sanderson, W. C. and S. Scherbov (2005). Average remaining lifetimes can increase as human populations age. Nature 435(7043), 811-813.

Sanderson, W. C. and S. Scherbov (2013). The characteristics approach to the measurement of population aging. Population and Development Review 39(4), 673-685.

Seshamani, M. and A. M. Gray (2004). A longitudinal study of the effects of age and time to death on hospital costs. Journal of health economics 23(2), 217-235.

Stearns, S. C. and E. C. Norton (2004). Time to include time to death? the future of health care expenditure predictions. Health economics 13(4), $315-327$.

Sullivan, D. (1971). A single index of mortality and morbidity. HSMHA Health Reports 86, 347-354.

United Nations, Department of Economic and Social Affairs, Population Division (2013). World population prospects: The 2012 revision, key findings and advance tables. Technical report, United Nations.

van Raalte, A. and T. Riffe (2016). Accounting for temporal variation in morbidity. Presented at the Annual Meeting of the Population Association of America.

van Solinge, H. and K. Henkens (2010). Living longer, working longer? the impact of subjective life expectancy on retirement intentions and behaviour. The European Journal of Public Health 20(1), 47-51.

Vaupel, J. W. (2009). Life lived and left: Carey's equality. Demographic Research 20(3), 7-10.

Villavicencio, F. and T. Riffe (2016). Symmetries between life lived and left in finite stationary populations. Demographic Research 35(14), 381-398. 
Weir, D., J. Faul, and K. Langa (2011). Proxy interviews and bias in the distribution of cognitive abilities due to non-response in longitudinal studies: a comparison of hrs and elsa. Longitudinal and life course studies 2(2), 170 .

Werblow, A., S. Felder, and P. Zweifel (2007). Population ageing and health care expenditure: a school of red herrings? Health economics 16(10), 1109-1126.

Wolf, D. A., V. A. Freedman, J. I. Ondrich, C. L. Seplaki, and B. C. Spillman (2015). Disability trajectories at the end of life: A countdown model. The Journals of Gerontology Series B: Psychological Sciences and Social Sciences 70(5), 745-752.

\section{Appendix: Variables and correlations}

For tables displayed in this appendix we use a shorthand to identify axis types. $\mathrm{T}$ indicates the correlation coefficient along the thanatological age axis. A indicates the chronological age axis. L indicates the lifespan axis (right-downward slanting isolines), the least common in these data. M indicates the mixed axis, upward-right slanting isolines, the most common type in these data. The code used to generate these and all other results, including results for all 5-year cohorts from 1905-1925 and different degrees of smoothing, is available freely the repository. The repository also contains a csv of these summary results.

https://github.com/timriffe/ThanoEmpirical

Results are grouped by several major morbidity categories and presented in heatmap tables. In these tables, darker shades of grey indicate higher correlations (black $=1$ ), and lighter grays indicate low correlations (white $=0$ ). Numbers inside the cells indicate the rounded Pearson's correlation coefficient $\times 100$, and can be interpreted as percents.

Finally, it bears noting that these values say nothing of prevalence levels. They are only intended to be rough gauges of the direction of variation in characteristics.

\section{List of Appendix Tables}

1 Activities of Daily Living (ADL) . . . . . . . . . . . 25

2 Instrumental Activities of Daily Living (IADL) . . . . . . 26 
3 Health behaviors . . . . . . . . . . . . . 26

4 Functional limitations . . . . . . . . . . . . . 27

5 Chronic conditions . . . . . . . . . . . . . 28

6 Cognitive function . . . . . . . . . . . . . . . . . 29

$7 \quad$ Psychological wellbeing $\ldots \ldots \ldots \ldots$

8 Healthcare use $(24$ months $) \ldots \ldots . \ldots . \ldots . \ldots 31$ 
Table 1: Activities of Daily Living (ADL)

\begin{tabular}{|c|c|c|c|c|c|c|c|c|c|}
\hline \multirow[t]{2}{*}{ Short } & \multirow[t]{2}{*}{ Description } & \multicolumn{4}{|c|}{ Females } & \multicolumn{4}{|c|}{ Males } \\
\hline & & $\mathrm{L}$ & $\mathrm{A}$ & $\mathrm{T}$ & M & L & $A$ & $\mathrm{~T}$ & $\mathrm{M}$ \\
\hline ADL3 & ADL 3 point & 25 & 80 & 80 & 96 & 9 & 67 & 84 & 89 \\
\hline ADL5 & ADL 5 point & 23 & 79 & 81 & 97 & 5 & 65 & 87 & 89 \\
\hline WALK & $\begin{array}{l}\text { Difficulty walking } \\
\text { across room }\end{array}$ & 16 & 73 & 83 & 93 & 6 & 53 & 86 & 80 \\
\hline DRESS & $\begin{array}{l}\text { Difficulty } \\
\text { dressing }\end{array}$ & 18 & 75 & 82 & 94 & 8 & 66 & 85 & 89 \\
\hline BATH & $\begin{array}{l}\text { Difficulty bathing } \\
\text { or showering }\end{array}$ & 17 & 73 & 81 & 94 & 7 & 59 & 83 & 82 \\
\hline EAT & Difficuty eating & 19 & 70 & 72 & 91 & 15 & 65 & 79 & 85 \\
\hline BED & $\begin{array}{l}\text { Difficuty getting } \\
\text { in/out bed }\end{array}$ & 14 & 71 & 82 & 93 & 8 & 59 & 80 & 80 \\
\hline TOILET & $\begin{array}{l}\text { Difficulty using } \\
\text { toilet }\end{array}$ & 31 & 81 & 73 & 94 & 0 & 51 & 81 & 78 \\
\hline
\end{tabular}


Table 2: Instrumental Activities of Daily Living (IADL)

\begin{tabular}{|c|c|c|c|c|c|c|c|c|c|}
\hline \multirow[t]{2}{*}{ Short } & \multirow[t]{2}{*}{ Description } & \multicolumn{4}{|c|}{ Females } & \multicolumn{4}{|c|}{ Males } \\
\hline & & $\mathrm{L}$ & A & $\mathrm{T}$ & M & L & A & $\mathrm{T}$ & M \\
\hline IADL3 & IADL 3 point & 28 & 82 & 78 & 97 & 6 & 66 & 88 & 91 \\
\hline IADL5 & IADL 5 point & 14 & 74 & 87 & 96 & 7 & 68 & 89 & 92 \\
\hline WORK & $\begin{array}{l}\text { Health limits } \\
\text { work }\end{array}$ & 25 & 36 & 98 & 73 & 6 & 53 & 93 & 84 \\
\hline MAP & $\begin{array}{l}\text { Difficulty using } \\
\text { maps }\end{array}$ & 24 & 77 & 78 & 94 & 13 & 67 & 80 & 88 \\
\hline TEL & $\begin{array}{l}\text { Difficulty using } \\
\text { telephone }\end{array}$ & 33 & 83 & 68 & 96 & 20 & 75 & 78 & 95 \\
\hline MONEY & $\begin{array}{l}\text { Difficulty } \\
\text { managing money }\end{array}$ & 21 & 76 & 81 & 95 & 1 & 56 & 90 & 84 \\
\hline MEDS & $\begin{array}{l}\text { Difficulty taking } \\
\text { medications }\end{array}$ & 24 & 75 & 77 & 95 & 3 & 45 & 94 & 73 \\
\hline SHOP & $\begin{array}{l}\text { Difficulty grocery } \\
\text { shopping }\end{array}$ & 2 & 65 & 91 & 91 & 8 & 54 & 91 & 84 \\
\hline MEALS & $\begin{array}{l}\text { Difficulty prep. } \\
\text { hot meals }\end{array}$ & 20 & 76 & 82 & 95 & 6 & 60 & 88 & 85 \\
\hline
\end{tabular}

Table 3: Health behaviors

\begin{tabular}{l|lcc|c|c|c|c|c|c} 
Short & Description & \multicolumn{4}{|c}{ Females } & \multicolumn{4}{c}{ Males } \\
& & L & A & T & M & L & A & T & M \\
\hline ALCEV & $\begin{array}{l}\text { Alcohol, } \\
\text { ever-drinker }\end{array}$ & 40 & 79 & 62 & 88 & 8 & 41 & 78 & 68 \\
ALCDAYS & $\begin{array}{l}\text { Drinking days / } \\
\text { week }\end{array}$ & 10 & 48 & 77 & 72 & 18 & 40 & 77 & 67 \\
ALCDRINKS & $\begin{array}{l}\text { N drinks per } \\
\text { drinking day }\end{array}$ & 28 & 84 & 75 & 96 & 18 & 49 & 89 & 80 \\
SMOKEEV & $\begin{array}{l}\text { Ever-smoker } \\
\text { SMOKECUR }\end{array}$ & 98 & 81 & 27 & 48 & 87 & 68 & 30 & 37 \\
\hline
\end{tabular}


Table 4: Functional limitations

\begin{tabular}{l|lcccccccc|c} 
Short & Description & \multicolumn{4}{c}{ Females } & \multicolumn{5}{c}{ Males } \\
BMI & L & A & T & M & L & A & T & M \\
\hline BACK & Body mass index & 34 & 79 & 72 & 93 & 4 & 54 & 91 & 83 \\
MOB & $\begin{array}{l}\text { Back problems } \\
\text { Mobility } \\
\text { difficulty index } \\
\text { Large muscle } \\
\text { difficulty index } \\
\text { Gross motor } \\
\text { difficulty index }\end{array}$ & 56 & 91 & 43 & 82 & 79 & 92 & 17 & 74 \\
GRMUS & 16 & 76 & 86 & 97 & 1 & 64 & 92 & 92 \\
Fine motor & 71 & 88 & 94 & 5 & 65 & 87 & 89 \\
\hline difficulty index & 22 & 78 & 81 & 96 & 14 & 70 & 81 & 90 \\
\hline
\end{tabular}


Table 5: Chronic conditions

\begin{tabular}{|c|c|c|c|c|c|c|c|c|c|}
\hline \multirow[t]{2}{*}{ Short } & \multirow[t]{2}{*}{ Description } & \multicolumn{4}{|c|}{ Females } & \multicolumn{4}{|c|}{ Males } \\
\hline & & L & A & $\mathrm{T}$ & M & L & A & $\mathrm{T}$ & M \\
\hline $\mathrm{CC}$ & $\begin{array}{l}\text { Number of } \\
\text { chronic }\end{array}$ & 34 & 82 & 77 & 98 & 7 & 53 & 95 & 84 \\
\hline $\mathrm{BP}$ & $\begin{array}{l}\text { conditions } \\
\text { High blood } \\
\text { pressure, ever }\end{array}$ & 14 & 67 & 84 & 89 & 37 & 84 & 75 & 98 \\
\hline DIAB & Diabetes, ever & 72 & 22 & 80 & 21 & 69 & 28 & 65 & 10 \\
\hline CANCER & Cancer, ever & 29 & 31 & 96 & 68 & 17 & 41 & 93 & 75 \\
\hline LUNG & Lung disease & 62 & 7 & 88 & 36 & 90 & 50 & 65 & 7 \\
\hline HEART & $\begin{array}{l}\text { Heart problems, } \\
\text { ever }\end{array}$ & 26 & 78 & 82 & 97 & 23 & 37 & 96 & 73 \\
\hline STROKE & Stroke, ever & 46 & 90 & 69 & 99 & 9 & 51 & 95 & 82 \\
\hline PSYCH & $\begin{array}{l}\text { Psychological } \\
\text { problems, ever }\end{array}$ & 33 & 77 & 69 & 88 & 24 & 37 & 96 & 72 \\
\hline ARTH & Arthritis, ever & 75 & 92 & 28 & 82 & 69 & 91 & 33 & 84 \\
\hline
\end{tabular}


Table 6: Cognitive function

\begin{tabular}{|c|c|c|c|c|c|c|c|c|c|}
\hline \multirow[t]{2}{*}{ Short } & \multirow[t]{2}{*}{ Description } & \multicolumn{4}{|c|}{ Females } & \multicolumn{4}{|c|}{ Males } \\
\hline & & $\mathrm{L}$ & $\mathrm{A}$ & $\mathrm{T}$ & M & $\mathrm{L}$ & A & $\mathrm{T}$ & M \\
\hline SRM & $\begin{array}{l}\text { Self-rated } \\
\text { memory }\end{array}$ & 51 & 92 & 65 & 99 & 60 & 70 & 16 & 60 \\
\hline PASTMEM & $\begin{array}{l}\text { Memory } \\
\text { compared to past }\end{array}$ & 61 & 87 & 41 & 85 & 71 & 94 & 36 & 87 \\
\hline SS & Serial 7s & 1 & 64 & 92 & 91 & 7 & 48 & 60 & 65 \\
\hline $\mathrm{C} 20 \mathrm{~B}$ & $\begin{array}{l}\text { Backwards } \\
\text { counting }\end{array}$ & 35 & 81 & 66 & 90 & 30 & 79 & 72 & 93 \\
\hline NAMEMO & Naming month & 33 & 80 & 67 & 90 & 2 & 49 & 72 & 70 \\
\hline NAMEDMO & $\begin{array}{l}\text { Naming day of } \\
\text { month }\end{array}$ & 24 & 78 & 78 & 94 & 21 & 75 & 78 & 92 \\
\hline NAMEYR & Naming year & 44 & 88 & 64 & 95 & 19 & 74 & 80 & 93 \\
\hline NAMEDWK & $\begin{array}{l}\text { Naming day of } \\
\text { week }\end{array}$ & 16 & 72 & 80 & 91 & 20 & 70 & 73 & 86 \\
\hline NAMESCI & Naming scissors & 50 & 87 & 53 & 88 & 12 & 42 & 78 & 69 \\
\hline NAMECAC & Naming cactus & 39 & 86 & 68 & 95 & 56 & 86 & 45 & 84 \\
\hline NAMEPRES & Naming president & 17 & 74 & 82 & 93 & 59 & 3 & 81 & 37 \\
\hline NAMEVP & $\begin{array}{l}\text { Naming vice } \\
\text { president }\end{array}$ & 1 & 52 & 74 & 74 & 4 & 58 & 79 & 81 \\
\hline VOCAB & Vocabulary score & 40 & 10 & 67 & 42 & 51 & 13 & 85 & 53 \\
\hline TM & $\begin{array}{l}\text { Mental status } \\
\text { summary }\end{array}$ & 19 & 76 & 83 & 96 & 10 & 66 & 81 & 87 \\
\hline DWR & $\begin{array}{l}\text { Delayed word } \\
\text { recall }\end{array}$ & 4 & 59 & 87 & 85 & 19 & 71 & 82 & 92 \\
\hline TWR & Total word recall & 19 & 71 & 82 & 92 & 27 & 76 & 77 & 93 \\
\hline IWR & $\begin{array}{l}\text { Delayed word } \\
\text { recall }\end{array}$ & 33 & 80 & 76 & 96 & 35 & 80 & 71 & 93 \\
\hline
\end{tabular}


Table 7: Psychological wellbeing

\begin{tabular}{l|lcc|c|c|c|c|c|c|} 
Short & Description & \multicolumn{4}{|c}{ Females } & \multicolumn{4}{c}{ Males } \\
& & L & A & T & M & L & A & T & M \\
\hline CESD & Depression score & 44 & 19 & 91 & 58 & 22 & 43 & 95 & 78 \\
SRH & $\begin{array}{l}\text { Self-reported } \\
\text { health }\end{array}$ & 42 & 14 & 90 & 53 & 29 & 33 & 98 & 70 \\
DEPR & Felt depressed & 55 & 19 & 58 & 13 & 58 & 4 & 86 & 38 \\
SLEEP & Sleep restless & 45 & 4 & 65 & 28 & 55 & 3 & 91 & 45 \\
HAPPY & Was happy & 33 & 15 & 76 & 47 & 15 & 60 & 72 & 78 \\
LONE & Felt lonely & 32 & 64 & 50 & 71 & 7 & 64 & 90 & 90 \\
SAD & Felt sad & 69 & 39 & 47 & 7 & 22 & 35 & 91 & 69 \\
GOING & $\begin{array}{l}\text { Could not get } \\
\text { going }\end{array}$ & 70 & 15 & 87 & 30 & 22 & 36 & 92 & 70 \\
ENJOY & Enjoyed life & 13 & 40 & 85 & 70 & 42 & 85 & 67 & 95 \\
\hline
\end{tabular}


Table 8: Healthcare use (24 months)

\begin{tabular}{|c|c|c|c|c|c|c|c|c|c|}
\hline \multirow[t]{2}{*}{ Short } & \multirow[t]{2}{*}{ Description } & \multicolumn{4}{|c|}{ Females } & \multicolumn{4}{|c|}{ Males } \\
\hline & & $\mathrm{L}$ & $\mathrm{A}$ & $\mathrm{T}$ & M & $\mathrm{L}$ & A & $\mathrm{T}$ & M \\
\hline HOSP & $\begin{array}{l}\text { Overnight } \\
\text { hospital }\end{array}$ & 26 & 73 & 75 & 90 & 11 & 60 & 77 & 81 \\
\hline HOSPSTAYS & $\begin{array}{l}\text { Number hospital } \\
\text { stays }\end{array}$ & 5 & 57 & 80 & 83 & 4 & 50 & 86 & 78 \\
\hline $\begin{array}{l}\text { HOSP- } \\
\text { NIGHTS }\end{array}$ & $\begin{array}{l}\text { Number nights in } \\
\text { hospitals }\end{array}$ & 10 & 40 & 77 & 70 & 61 & 6 & 87 & 36 \\
\hline $\mathrm{NH}$ & $\begin{array}{l}\text { Overnight stay in } \\
\text { nursing home }\end{array}$ & 25 & 75 & 67 & 94 & 13 & 64 & 78 & 82 \\
\hline NHSTAYS & $\begin{array}{l}\text { Nursing home } \\
\text { stays }\end{array}$ & 26 & 76 & 67 & 94 & 10 & 57 & 77 & 78 \\
\hline NHNIGHTS & $\begin{array}{l}\text { Number nights in } \\
\text { nursing homes }\end{array}$ & 18 & 70 & 70 & 89 & 13 & 61 & 80 & 80 \\
\hline NHNOW & $\begin{array}{l}\text { Nursing home at } \\
\text { interview }\end{array}$ & 14 & 72 & 71 & 93 & 8 & 46 & 80 & 73 \\
\hline $\mathrm{DOC}$ & Visited doctor & 63 & 89 & 40 & 85 & 52 & 85 & 52 & 88 \\
\hline DOCVISITS & $\begin{array}{l}\text { Number of doctor } \\
\text { visits }\end{array}$ & 54 & 91 & 58 & 95 & 33 & 70 & 56 & 79 \\
\hline $\mathrm{HHC}$ & Home health care & 18 & 71 & 84 & 94 & 2 & 52 & 90 & 84 \\
\hline MEDS & $\begin{array}{l}\text { Prescription } \\
\text { drugs regularly }\end{array}$ & 22 & 40 & 90 & 73 & 23 & 41 & 92 & 75 \\
\hline SURG & $\begin{array}{l}\text { Outpatient } \\
\text { surgery }\end{array}$ & 32 & 11 & 31 & 7 & 30 & 17 & 18 & 3 \\
\hline DENT & Visited dentist & 84 & 33 & 75 & 14 & 27 & 11 & 55 & 35 \\
\hline $\mathrm{SHF}$ & $\begin{array}{l}\text { Visited special } \\
\text { healthcare facility }\end{array}$ & 35 & 87 & 75 & 99 & 12 & 71 & 87 & 94 \\
\hline
\end{tabular}

